\title{
TRABALHO DOCENTE E O NOVO PLANO NACIONAL DE EDUCAÇÃO: VALORIZAÇÃO, FORMAÇÃ̃O E CONDIÇÕES DE TRABALHO
}

\author{
Álvaro Luiz M. Hypolito*
}

RESUMO: Este artigo discute o trabalho docente na Escola Básica e as novas perspectivas indicadas pelo Plano Nacional de Educação (PNE), em particular as indicaçôes que se relacionam com a valorização, a formação e as condiçōes de trabalho. Há boas expectativas no novo PNE quanto às formas de financiamento para a Educação Básica, mas muitas dúvidas quanto às formas de avaliação da educação e suas repercussôes sobre o trabalho docente. Sabe-se que políticas direcionadas à valorização docente são muito necessárias para que se obtenha uma condiçáo de trabalho docente valorizado. No mesmo sentido seguem as políticas de formação e de condiçóes de trabalho que devem ser alvo de fortes investimentos para que o trabalho docente possa ascender a uma condição mais digna de trabalho. Todavia, o PNE é uma oportunidade para pressôes e novos embates a fim de que obtenha um novo e importante avanço para a condição docente.

Palavras-chave: Trabalho docente. PNE. Valorização. Formação. Condiçóes de trabalho. Escola Básica.

\footnotetext{
* Pró-reitor de Graduação, Universidade Federal de Pelotas, Pelotas, MG., Brasil. E-mail de contato: alvaro.hypolito@gmail.com
} 


\title{
Teachers' work and the new National Education Plan (PNE): professional development, training and working conditions
}

\begin{abstract}
This article discusses teachers' work in Basic Education (Elementary, Middle and High School) and the new perspectives pointed by the National Education Plan (PNE), particularly the aspects related to professional development, training and working conditions. There are strong expectations in the new PNE as to ways of funding basic education, but, on the other hand, there are many questions concerning the forms of evaluating education as well as its impact on the teaching work. It is known that policies aimed at teacher development are strongly necessary so that we have a valued working condition. In the same vein, continuing education policies and working conditions must be the target of strong investment so that teachers' work can ascend to a more dignified working condition. However, the PNE is an opportunity for pressures and new conflicts so that a new and important development for the teaching condition can be achieved.
\end{abstract}

Keywords: Teachers' work. PNE. Teacher development. Continuing education. Working conditions. Basic education.

\section{INTRODUÇÃO}

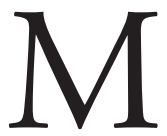

uitas análises relacionam as políticas educacionais brasileiras à influência de agências internacionais e aos modelos gerenciais de educação implementados em vários países, tais como Estados Unidos e Inglaterra, conforme inúmeras análises disponíveis na literatura. As sucessivas políticas educacionais brasileiras são, regra geral, uma aplicação em contexto local de políticas globais, muitas vezes descontextualizadas. ${ }^{1}$ Pouco tem-se prestado a atenção nas críticas e nas autocríticas desenvolvidas por muitos pesquisadores e educadores. Algumas dessas críticas são notáveis e devemos olhar com muita atenção, como as que são apresentadas nos livros de Diane Ravitch $(2011$; 2013). 
Nesse sentido, utilizo-me da bem conhecida e respeitada pesquisadora Linda Darling-Hammond para demonstrar como argumentos consistentes são desprezados pelos formuladores de políticas que somente enxergam o que desejam: testes e avaliação. Darling-Hammond (2015, p. 133), recentemente, ao discutir os testes e medidas de valor agregado, afirma que:

Há décadas, a partir de pesquisas educacionais, sabemos que muitas coisas são importantes para o desempenho dos estudantes além do trabalho individual do professor, outras coisas importam para este desempenho em vários momentos em determinadas áreas. Uma lista parcial inclui o seguinte:

- Fatores escolares, tais como tamanho das turmas, escolhas curriculares, tempo de ensino, disponibilidade de especialistas, tutores, livros, computadores, laboratórios científicos, e outros recursos;

- Experiência anterior de escolaridade e docentes, assim como outros aspectos das experi6encias mais atuais - tais como oportunidades de aprendizagem profissional e planejamento colaborativo;

- Cultura de pares e desempenho;

- Diferencial de ganhos e perdas na aprendizagem de verão (férias);

- Fatores domésticos, tais como capacidade dos pais no auxílio aos trabalhos para casa, segurança com a alimentação e moradia, e apoio ou abuso físico e mental; e

- Necessidades individuais dos estudantes, saúde e assistência. [N.A.: tradução livre]

Daling-Hammond, considerando a influência de todos esses aspectos para a aprendizagem, continua afirmando que "[...] não é surpresa que a docência represente apenas uma pequena parcela na variação de desempenho, tipicamente estimada em menos de $10 \%[\ldots] ”$. E en- 
cerra seu argumento mostrando que a própria Associação Americana de Estatística (ASA), ao se manifestar sobre o tema, afirma que a influência dos professores na variabilidade de resultados dos testes gira em torno de 1 a $14 \%$, e que classificar os docentes de acordo com os resultados de testes de avaliação pode ter consequências indesejáveis que reduzem a qualidade. (DARLING-HAMMOND, 2015, p. 133)

Utilizo-me desta passagem para mostrar que, ao contrário do que as evidências e as pesquisas demonstram, ao longo de décadas os reformadores e suas políticas educativas têm usado argumentos inadequados para culpabilizar o professorado e sua formaçáo pelo desempenho medíocre da educação brasileira, o que não está, ao contrário do que dizem, baseado em evidências.

É nesse contexto local das políticas educativas que pretendo discutir as políticas de valorização, formação e condiçóes de trabalho do professorado relacionadas com o Plano Nacional de Educação (PNE). Pretendo igualmente discutir os descaminhos e equívocos das políticas gerencialistas $^{2}$ que vêm sendo adotadas na educação pública brasileira, caracterizadas pela adoção de índices, medidas e exames padronizados, pela adoção de políticas de avaliação e accountability, por políticas de formação docente mais pragmáticas e pela pouca valorização docente.

Para travar essa discussão, o texto está estruturado em duas seçôes, uma que relaciona a valorização profissional e a formação docente no contexto do PNE, explorando as metas referentes a esses temas problematizando-as em confronto com as políticas educacionais atuais, $\mathrm{e}$ a segunda seção se concentra mais nas discussôes do trabalho docente em relação às políticas de salário e condições de trabalho vigentes.

\section{O PLANO NACIONAL DE EDUCAÇÃO E A VALORIZAÇÃO E FORMAÇÃO DOCENTE}

O PNE surge de uma discussão ampla da sociedade em torno dos debates realizados pelas duas Conferências Nacionais de Educação (CONAE), que envolveram inúmeros atores sociais, tais como educadores, sindicalistas, pais, estudantes, representantes de comunidades, 
dentre outros setores sociais. Todavia, o texto do PNE, que deveria estar baseado nas deliberaçóes dessas conferências, sofreu mutaçoos extraordinárias desde suas primeiras versóes e foi sofrendo, no decorrer de sua elaboração final, significativas mudanças que pretendiam adulterar o significado original de muitas proposiçóes. Algumas foram mantidas e melhoradas pela intervenção firme e decidida de associaçôes acadêmicas, sindicatos e movimentos sociais, outras foram introduzidas, de forma sub-reptícia, para atender interesses que nunca haviam se manifestado nas conferências. Trata-se, na maioria, de inclusóes apresentadas por deputados ou pelo relator do PNE na Câmara dos Deputados, por influência de lobbies privatistas, conservadores, que advogam uma submissão, endógena ou exógena, ${ }^{3}$ da escola pública ao mercado, a fim de garantir suas pretensóes em termos de políticas educacionais, por meio de um "atalho" político para influenciar deputados, relatores e membros de comissôes do parlamento, com seus experts e think tanks, que compõem as inúmeras organizações, fundações, institutos, com ou sem fins lucrativos, denominados reformadores empresariais, por Luiz Carlos Freitas (2014).

Em certos aspectos o PNE consegue expressar alguns anseios da comunidade educacional progressista e comprometida com a educação pública, tais como políticas de valorização docente, formação profissional, assim como o aumento do financiamento da educação (10\% do PIB) - Meta 20, embora com uma formulação aquém do que desejavam os movimentos sociais.

O Plano Nacional de Educação é paradoxal em alguns temas, ambíguo em outros, ora incompleto e deficiente em muitas temáticas. Por exemplo, se, por um lado, o plano define um aumento do financiamento para a educação, por outro lado, apresenta inúmeras metas ${ }^{4}$ que seguem as políticas gerencialistas de avaliação e de parceria público-privada, o que para muitos de nós é investir em um "saco sem fundo", que promove políticas privatistas, e não indica um investimento na educação pública de forma plena.

A precarização do trabalho docente e as péssimas condiçóes físicas e materiais das escolas públicas exigem um investimento direto e objetivo na educação pública, a fim de que se obtenha, de uma vez por todas, escolas com um padrão mínimo de qualidade - tanto em termos 
de prédios, bibliotecas, laboratórios, salas de aula etc., como em termos de materiais didáticos e recursos de ensino -, assim como políticas de valorização docente que garantam uma formação sólida, uma carreira profissional e uma retribuição salarial para o magistério que transforme este trabalho em algo digno, atrativo e prestigioso.

A valorização profissional e a formação docente são os temas das Metas 15, 16, 17 e 18, contudo esses temas podem ser identificados em outras metas, direta ou indiretamente. A seguir são apresentados de forma sintética as metas e suas estratégias sobre a formação e a valorização profissional conforme estão no PNE.

\subsection{A FORMAÇÃO DOCENTE NO PNE}

Como afirmado anteriormente, a formação inicial e/ou continuada é mencionada em várias metas do PNE, muitas vezes de forma secundária, relacionada com a meta em uma das estratégias para designar uma necessidade de formação específica. A Meta 1, que trata da Educação Infantil prevê na estratégia 1.8 " [...] promover a formação inicial e continuada dos/as profissionais da educaçáo infantil, garantindo, progressivamente, o atendimento por profissionais com formação superior [...]”. (BRASIL, 2014) Na Meta 3, que trata do Ensino Médio e aumento da taxa de matrícula neste nível de ensino, prevê como primeira estratégia, uma renovação curricular e do ensino, e indica a necessidade de uma formação continuada de professores. $\mathrm{O}$ mesmo acontece com a Meta 4, que trata na estratégia 4.3 da educação para grupos com necessidades especiais e prevê o fomento de "[...] formaçáo continuada de professores e professoras para o atendimento educacional especializado nas escolas urbanas, do campo, indígenas e de comunidades quilombolas [...]". (BRASIL, 2014) A Meta 5 refere-se à alfabetização de crianças até o terceiro ano e, para isso, promete na estratégia 5.6 promover e estimular a formação inicial e continuada de professoras(as) para a alfabetização, articulada com programas de pós-graduação stricto sensu.

A Meta 7 trata da melhoria da qualidade da educação básica em todas as etapas e modalidades, entendida como melhoria do fluxo escolar e de aprendizagem, fixando médias nacionais para o Ideb, por 
isso, talvez, faça várias menções à formação, como necessidade para a melhoria do ensino. Na estratégia 7.4 aponta a autoavaliação das escolas, e a necessidade de um instrumento para esta avaliação a fim de orientar dimensóes, tais como o planejamento estratégico, a melhoria contínua da qualidade, a formação continuada dos(as) profissionais da educação e o aprimoramento da gestão democrática. A estratégia 7.5 indica a necessidade de planos de açóes articuladas, voltadas à formação de professores e professoras e profissionais de serviços e apoio escolares, dentre outros aspectos pedagógicos e físico-materiais para a expansão da rede escolar. As estratégias 7.26 e 7.33 fazem, respectivamente, referência à formação específica para a educação no campo, de indígenas e comunidades quilombolas, e à capacitação de professores e professoras para atuarem na formaçáo de leitores, de acordo com o Plano Nacional do Livro e da Leitura. A estratégia 7.34 fala de um "programa nacional de formação de professores e professoras", sem deixar muito evidente o tipo de programa, somente refere-se a uma política de preservação da memória nacional.

As Metas 9 e 10 tratam da Alfabetização, da Educação de Jovens e Adultos e da Educação Profissional. Em ambas as metas está previsto um incentivo à formação específica, seja para a educação de apenados ou para a EJA articulada com a educação profissional. A Meta 12 define como uma prioridade da Educação Superior Pública a formação inicial de professores, em especial para o Ensino de Ciências e Matemática e outras áreas específicas. Em outra estratégia desta meta, novamente prevê-se a formação para atender populaçóes do campo, indígenas e quilombolas, o que aparece em várias partes do PNE.

As Metas 15 e 16 tratam mais diretamente da formação docente. A primeira propõe, no prazo de um ano, uma política nacional de formaçấo dos profissionais de educação que assegure a formação de nível superior, em cursos de licenciatura. Inclui, dentre suas estratégias: ampliar programa permanente de iniciação à docência a estudantes em cursos de licenciatura (Pibid); consolidar e ampliar plataforma eletrônica para organizar a oferta e as matrículas em cursos de formação inicial e continuada de profissionais da educaçáo - por onde tem-se organizado o Parfor ${ }^{5}$; enfatizar a necessidade de programas específicos - escolas do campo e de comunidades indígenas e quilombolas, além da educação 
especial (tema redundante); propor a reforma dos cursos de licenciatura articulada com a base nacional comum dos currículos da educação básica; garantir a implementação de novas diretrizes curriculares, por meio da avaliação, regulação e supervisão da educação superior; valorizar as práticas de ensino e estágios nos cursos de formação, visando uma articulação da formação e das demandas da educação básica; implementar cursos e programas especiais para dar formação de nível superior aos docentes com formação de nível médio em efetivo exercício; criar programa de bolsas para docentes de idiomas a fim de realizarem estudos de imersão e aperfeiçoamento no exterior; desenvolver modelos de formação docente para a educação profissional com cursos de complementação pedagógica e certificação de profissionais experientes, que valorizem a experiência prática.

A Meta 16 pretende induzir uma política de formação que atinja 50\% dos professores da educação básica, em nível de pós-graduação, e garantir formação continuada a todos nas suas respectivas áreas. Dentre as estratégias para atingir tal meta consta: um planejamento para dimensionar a demanda por formaçáo continuada e fomentar a oferta pelas instituiçóes públicas; a consolidação de política nacional de formação de professores da educação básica; a oferta ampliada de bolsas de estudo para pós-graduação; o fortalecimento da formação por meio das açóes do Plano Nacional do Livro e Leitura.

\subsection{A VALORIZAÇÃO PROFISSIONAL NO PNE}

A valorização profissional está relacionada com vários temas propostos pelo PNE, explícita ou implicitamente, e pode ser identificada ou relacionada com outros aspectos, em especial com a formaçáo. A estratégia 5.1, por exemplo, relaciona a qualificação e valorização de alfabetizadores como necessidade para alcançar uma plena alfabetização das crianças. Mas a Meta 17 e 18 é que estáo mais diretamente relacionadas com este tema.

A Meta 17 é voltada para a valorização do profissional do magistério e busca equiparar o rendimento médio dos docentes da educação básica pública ao rendimento dos demais profissionais de outras áreas 
com escolaridade equivalente. A diferença entre o rendimento médio do magistério comparado com outras categorias profissionais é de 57\%, conforme apontado por documento do MEC sobre o PNE. (MEC, 2014)

Como estratégias para o cumprimento desta Meta, o PNE propóe: o acompanhamento do valor do piso salarial nacional dos professores; o acompanhamento da evoluçáo salarial por meio de indicadores oficiais; a implementação em todas as esferas da federação planos de carreira para o magistério da rede pública, com implementação gradual da jornada em um único estabelecimento escolar; e, por fim, a ampliação da assistência financeira da União aos Estados para criar políticas de valorização profissional, em particular para garantir o piso salarial nacional.

A Meta 18 assegura que, no prazo de 2 (dois) anos, devem existir planos de Carreira para os profissionais da educação básica e superior pública de todos os sistemas de ensino. Para os profissionais da educação básica pública o plano de Carreira deve tomar como referência o piso salarial nacional profissional. As estratégias decorrentes desta meta preveem: que $90 \%$ dos profissionais do magistério e $50 \%$ dos profissionais não docentes, no mínimo, sejam ocupantes de cargos efetivos e em exercício nas redes escolares; que os profissionais iniciantes sejam supervisionados por profissionais experientes a fim de avaliar o estágio probatório, mesmo que com possibilidades de estudos na área de atuação; que os planos de carreira dos Estados, Distrito Federal e Municípios prevejam licenças remuneradas e incentivos para a qualificação profissional, incluindo Mestrado e Doutorado; que sejam estruturadas comissôes permanentes de profissionais da educação, em todas as instâncias para subsidiar a elaboração, reestruturação e implementação dos planos de carreira.

Apresentados os temas da Formação e da Valorização Profissional na forma como são apresentados no PNE, discute-se, na próxima seção, alguns significados e implicaçóes das concepçóes expressadas no plano para as políticas educacionais, para o trabalho docente e para a escola pública do ensino básico. 


\section{TRABALHO DOCENTE E AS POLÍTICAS EDUCACIONAIS DO PNE}

O PNE é impreciso em termos utilizados, pouco específico por vezes, ora repetitivo e redundante, acima de tudo é um plano confuso e paradoxal, um pouco por vício de origem, pela "colcha de retalhos" em que foi transformado, e por indefiniçôes da própria política educacional brasileira que há anos vem ensaiando políticas para a formação docente e não há definiçóes quanto a um sistema nacional de formação docente. Ademais, o plano é fragilizado por uma realidade que é confusa e desestruturada. Por exemplo, o problema do financiamento da educaçáo. Não basta discutir um percentual do PIB para a educação, há que se debater como os recursos serão utilizados, em que políticas educacionais serão aplicados. Os recursos da educação serão aplicados para fortalecer a escola pública e o professorado ou serão canalizados para sistemas de avaliação e parcerias público-privadas?

É certo que em políticas não há garantias. As políticas educacionais previstas no PNE, na Lei do Piso Salarial, ou em qualquer outra política, estarão dependentes das forças políticas e sociais em atuação, dos contextos econômicos e culturais, e são, em boa medida, contingentes, e, de certo modo, caóticas, como aponta Ball (2008). Considero, a partir dessa compreensão, que as políticas de formação estão ainda muito indefinidas e em disputa.

O que é possível depreender das formulaçôes que estão no PNE sobre formação é que são políticas muito concentradas na formação continuada, que é por onde as políticas podem migrar a cada momento com tonalidades diferentes. As especificidades que exigem formação específica, e muito por isso formação continuada, estão apresentadas para diferentes níveis - alfabetização, Ensino Médio etc.; diferentes grupos ou contextos - indígenas, quilombolas, educação do campo; diferentes modalidades - EJA, educação profissional; e assim por diante. É óbvio que há necessidades específicas que precisam ser atendidas e muitas por meio de formação continuada. Todavia, este tema é muito recorrente no plano, chega a ser repetitivo, para não dizer neurótico. 
A formação continuada prevê, o que é bem satisfatório, uma formação mais intensa em nível de Pós-graduação. Contudo, aqui igualmente há indícios de uma intencionalidade pragmática quando se volta para a formaçáo de áreas mais "técnicas", onde faltam professores, como ciências e matemática e outras áreas.

É estranho que a ideia de um sistema nacional de formação de professores não tenha avançado na prática, dado que há necessidade uma política nacional de formação. No plano esta política está desenhada de modo a incluir formação superior inicial - na forma inclusive de programas especiais, formação continuada específica e de pós-graduação, e a apontar novas diretrizes curriculares para as licenciaturas, com valorização da prática e permitindo a certificação da experiência.

Novamente é importante buscar a experiência de outros lugares. Embora longa, a citação a seguir pode elucidar um pouco o que está sendo apontado como problema da formação. Ao tratar da desprofissionalização docente, os autores afirmam:

Uma outra característica da desprofissionalização e da desqualificação, em termos mundiais, pode ser vista no reducionismo e na 'racionalização' dos cursos de formação docente e na abertura para novos tipos de cursos de capacitação, menos acadêmicos e mais flexíveis; por exemplo, 'Teach for America' nos EUA, 'Teach First' na Inglaterra, e mais recentemente "Teach for All', que está apoiando iniciativas no Brasil, Chile, Argentina, Israel, Líbano, China, Alemanha, Estônia, Letônia, Lituânia, Bulgária e Austrália. [...]. Essas iniciativas removem muito do conteúdo teórico e crítico da formaçáo docente e visam colocar estudantes recém graduados, os mais bem qualificados, em salas de aula de escolas "desafiadoras" após poucas semanas de treinamento para um compromisso de dois anos. Sáo iniciativas basicamente financiadas por corporaçôes filantrópicas, embora possam ser também subsidiadas com verba pública, e são o exemplo do aumento da presença do setor privado como peça chave, globalmente falando, para as políticas educacionais e para a prestação de serviços; a Fundação Bill e Melinda Gates é uma dentre inúmeras organizaçôes 
filantrópicas que, por exemplo, financiam Teach For America, e na Inglaterra vários bancos comerciais e de investimentos, tais como HSBC e Goldman Sachs, também estão muito envolvidos. (BALL et al, 2013, p.16-17)

É certo que esse tipo de programa não será apresentado como solução para a formação docente no Brasil, tão defasada e frágil, mas mostra uma tendência do gerencialismo para a compreensão de como deve ser a formação docente. Isso pode ter influência para dois aspectos importantes da formação, pelo menos. Um é enfraquecer a formação inicial nas faculdades de educação e nas universidades. Outro, decorrente deste, é demonstrar que o importante para ensinar é a prática. Portanto, a formação inicial e continuada pode ser realizada em centros apropriados para isso, que não são as universidades.

Algo similar está previsto no documento Pátria Educadora, preparado pela Secretaria de Assuntos Estratégicos - ligada à Presidência da República, divulgado em abril 2015 (versão preliminar para debate), quando indica a criação de Centros de Formação Avançada para professores e os Centros de Formação para Diretores, ligados ao Inep. Tal política vem sendo delineada há muito e já está em ação em alguns estados. Em Minas Gerais, por exemplo, o governo do estado criou a Magistra - a Escola da Escola, e desprezou a Universidade do Estado de Minas Gerais (UEMG), criando uma nova estrutura duplicando funções. O objetivo foi retirar da universidade a formação docente, submetendo-a a uma formação mais interessada para o ensino, mais pragmática, no sentido de atender aos objetivos das políticas educacionais.

O documento Pátria Educadora, recente e ainda pouco discutido, assume uma importância ímpar pois traduz de forma mais objetiva a política oficial para a educação e a formação, mostra a que veio e por onde a política oficial pretende construir o PNE e a Educação Básica até 2024. Nele fica muito evidente a articulação entre avaliação - sistema nacional de avaliação, currículo nacional e formação docente, o que já tem sido discutido amplamente. Processos gerenciais desse tipo têm sido catastróficos para o trabalho docente. ${ }^{6}$ 
O outro tema objeto deste artigo é a valorização profissional, que está relacionada não somente com a formação e a carreira, mas também com as condiçóes de trabalho, como expresso na citação seguinte.

A valorização profissional docente refere-se tanto a aspectos internos quanto externos à profissão. Possui, evidentemente, interfaces com o trabalho e suas condições de produção, mas possui interfaces muito determinantes com aspectos anteriores ou externos ao processo de trabalho, tais como formação, políticas de remuneração e carreira, políticas educacionais e, de modo especial, com o prestígio social que é atribuído ao trabalho docente. É uma relação complexa de influências recíprocas em que um fator influencia outros e é por eles influenciado. Isso pode soar simplista, mas o fato é que fatores externos, por exemplo, a formação, podem influenciar diretamente fatores internos ao processo de trabalho, afetando da mesma forma aspectos subjetivos, como vocaçấo e identidade. Ocorre que muitos desses cruzamentos não são percebidos no cotidiano por alguns docentes e por amplos setores sociais, o que faz com que relações mais diretamente identificáveis sejam atribuídas como ' $a s$ ' causas dos dilemas educativos. Como exemplo, o fato de os docentes serem apontados como responsáveis por sua própria formação e isso ser aceito por muitos docentes como algo natural e náo como um problema de carreira ou de políticas educacionais mais amplas. (HYPOLITO, 2012, p. 215)

A valorização profissional no PNE é trazida na forma de garantia de um aumento do rendimento médio, equiparado a outros profissionais, a planos de carreira, a assistência financeira da Uniâo para garantir o Piso Salarial Profissional Nacional em todo o país, enfim o plano relaciona carreira, piso e formação. Além de introduzir uma avaliação dos professores iniciantes por colegas experientes, próxima do que foi implantado no Chile, que na prática não se configurou como valorização, mas como controle e demissão de docentes, pois a avaliação sempre esteve associada ao desempenho das escolas nos exames padronizados. 
Sempre que se fala em remuneração, avaliação e percentual de financiamento do PIB, vem a mente os países que são comparados com o Brasil, em termos de desempenho na educação, para mostrar quais níveis de índices se deve chegar - Ideb, Pisa etc. Se a Finlândia é tomada como exemplo, fica demonstrado que há fatores que definem o resultado de seus alunos muito além dos exames. A educação finlandesa não está focada nos exames, não prepara seus estudantes para isso, seus professores são bem formados nas universidades e possuem mestrado, são muito bem remunerados - a profissão docente é das mais procuradas e bem prestigiada como profissão, os currículos não são impostos nacionalmente para facilitar a avaliação, dentre outros pontos que poderiam ser arrolados.

Outro caso, oposto ao da Finlândia, é os Estados Unidos que nos tem servido de parâmetro e, como aponta Diane Ravitch, a escola pública está afundando exatamente porque está assumindo políticas privatistas e gerencialistas, baseadas em exames, avaliação, accoutability e programas de terceirização, tais como as Charter Schools, ou contratos de gestão da rede pública e desvalorização dos professores e seus sindicatos.

Os sindicatos docentes têm afirmado que a valorização docente implica em uma carreira consistente, em uma remuneração salarial digna e uma formação sólida, além da garantia de boas condiçóes de trabalho. Por isso, a valorização profissional precisa ser melhor dimensionada. $\mathrm{O}$ que se pode garantir com 7 ou 10\% do PIB para a educação?

A resposta a esse questionamento impóe que se enfrente um desvio crônico do investimento em educação. Ao diagnosticar que o problema está na docência e na sua má formação, as políticas conservadoras das últimas quatro décadas são míopes e não querem enxergar que é preciso um investimento imenso para melhorar a infraestrutura e condiçôes de trabalho nas redes públicas de ensino. Há necessidade de um padrão mínimo de qualidade para as escolas e suas estruturas - desde prédios, bibliotecas, laboratórios e matérias pedagógicos -, para isso é necessário também melhorar as condiçôes de trabalho. A Lei do Piso ainda não é respeitada em muitos estados e na maioria dos municípios, não somente no que se refere ao valor do salário inicial, mas quanto ao $1 / 3$ (um terço) do tempo da carga horária que deve ser destinado ao preparo, planejamento e estudo. 
A melhoria das condiçôes de trabalho é crucial para revitalizar um trabalho muito precarizado, não há como se espelhar em outros países onde as condições de produção da educação são muito distintas daquelas a que estamos submetidos. Os recursos do PIB devem ser investidos sem corrupção e com foco na melhoria do sistema e das condiçóes de trabalho, garantia do piso nacional e de carreira que valorize a profissão docente, sob pena de mais uma década sem boas soluçóes educacionais.

\section{CONSIDERAÇÕES FINAIS: VALORIZAÇÃO, FORMAÇÃO E CONDIÇÕES DE TRABALHO}

O PNE para alguns é um avanço e pode ser perseguido com avanços para a educação pública se houver atuação que empodere as açóes políticas dos docentes e dos movimentos sociais progressistas, no sentido de fazer valer os pontos estimulantes e motivadores para a melhoria da educação.

Pouco foi tratado neste texto sobre o problema das parcerias público-privadas, que quando abordadas no $\mathrm{PNE}$, muitas vezes não aparecem de forma explícita, contudo é uma preocupação o desenvolvimento de políticas voltadas para favorecer essas parcerias em educação, como pode ser visto no dossiê organizado na revista Currículo sem Fronteiras (2013). Os sistemas apostilados estão se disseminando por todo o território. É uma forma de privatização e de controle sobre os processos de avaliação, de currículo padronizado e de exames, interfere sobremaneira no trabalho docente, tanto na definição do que ensinar quanto do como ensinar. Implica igualmente na formação docente e na valorização profissional.

O documento Pátria Educadora surge em um momento crucial e decisivo, quando muitas definiçóes sobre a implementação do PNE estão sendo tomadas. $\mathrm{O}$ documento aponta para um direcionamento baseado no gerencialismo, nas políticas de avaliação, no currículo nacional, nos centros de formação. É, pois, temerário que o PNE enverede por este caminho e as questôes da valorização profissional, das condiçôes de trabalho, da formação inicial universitária de qualidade e de uma formação continuada delineada não para atender ao sucesso das políticas 
avaliativas e do currículo nacional, mas voltada para um enriquecimento curricular que se oponha ao empobrecimento curricular imposto pelos exames padronizados.

No início do texto utilizei-me de uma passagem de Linda Darling-Hammond para mostrar como a docência influencia pouco nos resultados dos testes e que perseguir esta lógica de humilhar e culpar os professores pelo mau desempenho do sistema escolar não só está errada, como pode ainda aprofundar as dificuldades existentes. Insisto nesta ideia porque vejo há muitas décadas que o alvo está equivocado, de nada adianta fragilizar a formação, empobrecer o currículo, investir mal e pouco na estrutura escolar, se o que é preciso é justiça curricular para efetivar uma educação pública de qualidade.

É uma luta por hegemonia, por controle de significados, por controle do sentido das políticas. O PNE pode ser o que está sendo ou o que queiramos que seja.

\section{REFERÊNCIAS}

BALL, S. J. Novos Estados, nova governança e nova política educacional. In: APPLE, M.W.; BALL, S.J.; GANDIN, L.A. (Org.). Sociologia da Educação análise internacional. Porto Alegre: Penso, 2013.

. Global Education Inc. - new policy networks and the neo-liberal imaginary. New York: Routledge, 2012.

BALL, S. The education debate. Bristol: The Policy Press, 2008.

BALL, S. et al. A constituição da subjetividade docente no Brasil: um contexto global. Revista Educação em Questão, Natal, v. 46 n. 32, p. 9-36, mai./ago. 2013.

BRASIL. Lei n.13.005, de 25 de junho de 2014. Aprova o Plano Nacional de Educação - PNE e dá outras providências. Diário Oficial da Uniáo, Brasília, DF., 26 jun 2014. Disponível em: <https://www.planalto.gov.br/ccivil_03/_ ato2011-2014/2014/lei/113005.htm>.

. Ministério da Educação. Planejando a Próxima Década. Conhecendo as 20 Metas do Plano Nacional de Educação. Ministério da Educação/Secretaria de Articulação com os Sistemas de Ensino (MEC/Sase): Brasília, DF., 2014. 
BRASIL. Secretaria de Assuntos Estratégicos. Pátria Educadora: a qualificação do ensino básico como obra de construção nacional. SAE: Brasília, 2015. [Versão Preliminar].

CLARKE, J.; NEWMAN, J. The managerial state. London: Sage Publications, 1997.

DARLING-HAMMOND, L. Can Value Added Add Value to Teacher Evaluation? Educational Researcher, v. 44, n. 2, p. 132-137, 2015.

FREITAS, L. C. de. Os reformadores empresariais da educação e a disputa pelo controle do processo pedagógico na escola. Educ. Soc., Campinas, v. 35, n. 129, p. 1085-1114, out/dez, 2014.

HYPOLITO, Á. M. Estado gerencial, reestruturação educativa e gestão da educação. RBPAE, v. 24, n. 1, p. 63-78, jan/abr, 2008.

- Trabalho docente na educação básica no Brasil: as condições de trabalho. In: OLIVEIRA, D. A.; VIEIRA, L. F. Trabalho na Educação Básica: a condição docente em sete estados brasileiros. Belo Horizonte: Fino Traço, 2012.

NEWMAN, J.; CLARKE, J. Gerencialismo. Educação \& Realidade, Porto Alegre, v. 37, n. 2, p. 353-381, maio/ago. 2012. Disponível em: <http://www. ufrgs.br/edu realidade>.

PERONI, V. M. V.; ADRIÃO, T. (Orgs.). Seção Especial Temática - Privatização da educação no contexto da(s) "Terceira(s) Via(s)": uma caracterização em análise. Currículo sem Fronteiras, v. 13, n. 2, maio/ago. 2013.

RAVITCH, D. Vida e Morte do grande sistema escolar americano - como os testes padronizados e o modelo de mercado ameaçam a educação. Porto Alegre: Editora Sulina, 2011.

. Reign of error. The Hoax of the privatization movement and the danger to America's Public Schools. New York: Alfred Knopf, 2013.

\section{NOTAS}

1. Um pequeno exemplo, mas que a meu ver reflete essa apropriação descontextualizada, é a campanha sobre Diretor Principal do Ministério da Educação (MEC), cuja chamada parece ser uma alusão malfeita ao termo Principal (usado em inglês estadunidense para designar Diretor de Escola), no contexto brasileiro essa terminologia não tem significado, portanto nem a ambiguidade pretendida - se é que houve - foi alcançada. É no mínimo falta de criatividade. 
2. Sobre gerencialismo ver Clarke e Newman (1997); Newman e Clarke (2012); sobre gerencialismo e políticas educativas no Brasil, ver Hypolito (2008).

3. A respeito de privatização endógena e exógena ver Ball et al. (2013).

4. Ver, como exemplo, a Meta 7 do PNE.

5. Parfor - Plano Nacional de Formação de Professores da Educação Básica. Informações em: <http://www.capes.gov.br/educacao-basica/parfor>.

6. Ver, por exemplo, Hypolito e Ivo (2013); Ball et al. (2013); Hypolito; Vieira e Leite (2012)

Recebido em 01 de junho de 2015.

Aprovado em 15 de setembro de 2015.

DOI: http://dx.doi.org/10.1590/CC0101-32622015150376 